\title{
A Study on the Development of International E-Commerce Competency Model in China
}

\author{
Sheng Wang \\ Department of Foreign Languages, College of Ethnology, Lishui University, Lishui, China \\ Email: hero845@126.com
}

How to cite this paper: Wang, S. (2021). A Study on the Development of International E-Commerce Competency Model in China. American Journal of Industrial and Business Management, 11, 1153-1162. https://doi.org/10.4236/ajibm.2021.1112070

Received: October 26, 2021

Accepted: December 3, 2021

Published: December 6, 2021

Copyright $\odot 2021$ by author(s) and Scientific Research Publishing Inc. This work is licensed under the Creative Commons Attribution International License (CC BY 4.0).

http://creativecommons.org/licenses/by/4.0/

(c) (i) Open Access

\begin{abstract}
In recent years, China's international e-commerce has developed rapidly and has a huge demand for professional talents. This paper aims to investigate the ability and skills required by international e-commerce enterprises for employees and develop the competency model so as to cultivate international e-commerce talents who meet the demand. It employed a mixed research design and selected participants from small and medium-sized international e-commerce enterprises in one province in China. Questionnaire and interview were employed to collect data, which were analyzed by descriptive statistics and content analysis. It was found that competencies required of international e-commerce talents included three parts: foreign language competencies, competencies of international e-commerce and qualities of international e-commerce talents, based on which the competency model of international e-commerce was developed.
\end{abstract}

\section{Keywords}

International E-Commerce, Talents, Small and Medium-Sized Enterprises, Competency Model

\section{Introduction}

In recent years, China's international e-commerce (often referred to as cross-border e-commerce in China) has developed rapidly, with more and more international trade enterprises entering the international e-commerce. The rapid development of international e-commerce in China has a huge demand for professional talents. According to the survey by Jian Wang in University of International Business and Economics, there is a serious shortage of international e-commerce talents, reaching $86 \%$, and most international e-commerce enterprises cannot recruit talents they need (Wang, 2015). At the same time, products in markets 
sold by international e-commerce enterprises become diversified, which put forward higher requirements for international e-commerce talents. Therefore, talents who are competent for international e-commerce occupation in China are very scarce. According to the demand of international e-commerce, talents are those who know English, international trade and online store managing (Wang, 2015). International e-commerce requires inter-disciplinary talents. In China, few studies have been conducted to explore the international e-commerce competency model. Su (2016) has explored the international e-commerce competency model, but no competency model was proposed finally. Therefore, it is essential to develop international e-commerce competency model to satisfy the requirements of talents in China. This paper attempts to investigate the ability and skills required by international e-commerce enterprises for employees and develop the competency model so as to cultivate international e-commerce talents who meet the demand.

\section{Theoretical Basis}

\subsection{Definition of Competency}

McClelland (1973) was the first to conduct the research on professional ability and competency model, and thought that ability is an important predictor of job success, which is as important as knowledge and academic ability indicated by test results. Lucia and Lepsinger (1999) defined competency as a set of relevant knowledge, skills and attitudes that affect key parts of a job (role or responsibility), and that are relevant to job performance, measured by accepted standards and improved through training and development. It can be seen that ability includes not only skills, but also knowledge, quality and attitude. The international e-commerce capability should refer to a set of foreign language knowledge and skills and knowledge and skills related to international e-commerce, with foreign language knowledge and skills as its core.

\subsection{The Competency of International E-Commerce Talents}

The general competency consists of three parts: core competencies, general process competencies and production-supported competencies (Marrelli, 2010). Core competencies are those that all employees in a certain industry (or occupation) must master; general process competencies refer to a specific process competency that all employees must master except the core competencies; production-supported competencies refer to the ones that most employees in a certain industry (or occupation) need to master for specific production or production-support. According to the general competency model, the competencies of international e-commerce talents should include three components: foreign language (often referring to English in China) competencies, the general use of foreign language competencies and international e-commerce support competencies. The core competencies of English as a foreign language mainly include listening, speaking, reading, writing, translation and cross-cultural communica- 
tion; the general use of foreign language competencies refers to the competency to use foreign language in the whole process of international e-commerce.

This paper verifies the feasibility of the international e-commerce competency model transformed from Marrelli's competency model by investigating small and medium-sized international e-commerce enterprises in China, and modifies and improves it to be suitable for the needs of small and medium-sized international e-commerce enterprises in China. Specifically, it intends to answer the following two research questions:

RQ1: What are the components of international e-commerce competency model?

RQ2: What is specific content of each component?

\section{Method}

\subsection{Research Design}

The present study used a mixed research design, combining qualitative research method with quantitative research method, which investigates the competency requirements of international e-commerce enterprises in China from two dimensions of process and conclusion, in order to develop competency model of international e-commerce. Data collected by qualitative research techniques and quantitative research techniques corroborated each other to answer the two explorative research questions.

\subsection{Participants}

The participants were mainly selected from international e-commerce enterprises in Yiwu and Taizhou of Zhejiang Province in China by purposeful sampling. Yiwu is a mature area for international e-commerce and international e-commerce enterprises are mostly small and medium-sized and have been engaged in international e-commerce for many years. It is well-known for the trade center of small commodities. Taizhou is in the transition from traditional international trade to international e-commerce, which is in the initial stage of international e-commerce. There were 32 enterprises chosen for the questionnaire, among which 9 were chosen for interview.

\subsection{Instruments}

There were two data collection tools in the study: questionnaire and semi-structured interview. Questionnaire was mainly employed to collect quantitative data and semi-structured interview was used to collect qualitative data.

Based on the research questions, the questionnaire was constructed. Then, the experts were inquired for their opinions, according to which the modifications of questionnaire were conducted. Finally, the questionnaire was piloted and analyzed. The questionnaire consists of three parts: the general information of enterprises, the abilities and skills required of international e-commerce talents, and the difficulty of recruiting the talents. The questionnaire mainly employed 
the multiple-choice item format.

According to the research questions, a semi-structured interview was drawn up. Due to the fact that Chinese businessmen, cultivated by Confucian Culture, are unwilling to answer complex and open questions, closed-ended questions, open-ended questions and probe questions were used to elicit information as much as possible. The participants were informed of the purpose of the interview. Their privacy would be protected and not be revealed in future articles. The interview was recorded and then transcribed. Nine international e-commerce businessmen were interviewed.

\section{Results}

Descriptive statistical analysis was employed to analyze the quantitative data. The data collected by interview were coded first, and then content analysis was used to find out the categories and sub-categories, and compare and analyze the categories to explore the relationship between them.

\subsection{The Need of International E-Commerce Talents in Job Market}

Through descriptive statistical analysis of quantitative data collected by questionnaire, it was found that $75 \%$ of the surveyed enterprises carried out B2B international e-commerce business, and 25\% performed B2C (as shown in Table 1). $100 \%$ of the surveyed enterprises used Alibaba and 25\% used AliExpress and eBay, respectively. It indicates that most of China's international e-commerce enterprises engaged in global wholesale trade.

The international e-commerce talents they need are mostly foreign trade salesmen, online store managers and after-sales service staff, with the percentage of $100 \%, 74 \%$ and $52 \%$, respectively (as shown in Table 2). It indicates that foreign trade salesmen were more important than online store managers and in turn, than after-sales service staff. Foreign trade salesmen were in more need than online store managers and in turn, than after-sales service staff. Most of enterprises thought that it was difficult to find talents. They mainly recruited talents through talent supply meetings organized by universities, job market and recruitment agency. There was a great demand for talents in international e-commerce enterprises, and it was difficult for them to recruit qualified talents. Schools were still the main training channel for international e-commerce talents.

Table 1. International e-commerce platform and business mode.

\begin{tabular}{cc}
\hline Platform and Business Mode & Importance \\
\hline B2B & $75 \%$ \\
B2C & $25 \%$ \\
Alibaba.com & $100 \%$ \\
AliExpress & $25 \%$ \\
eBay & $25 \%$
\end{tabular}


Table 2. The demand of international e-commerce talents.

\begin{tabular}{cc}
\hline Occupation & Importance \\
\hline Online store manager & $74 \%$ \\
Foreign trade salesman & $100 \%$ \\
After-sales service staff & $52 \%$ \\
Staff for official documents and correspondence & $23 \%$ \\
Warehouse keeper & $25 \%$ \\
Offline purchaser & $24 \%$ \\
\hline
\end{tabular}

\subsection{Ability and Quality Required of International E-Commerce Talents English Ability}

The surveyed enterprises realized the importance of English ability in international e-commerce, among which $76 \%$ thought that oral English should be fluent, followed by English writing ability and cross-cultural communication, both of which were 51\%, and finally English reading ability, with the percentage of 45\% (as shown in Table 3). This shows that spoken English was extremely important in international e-commerce, and customer development and maintenance needed fluent spoken English and cross-cultural communication skills; secondly, English writing ability was particularly important in the management of international e-commerce online shops.

The above findings were verified by interviews, in which many participants mentioned the importance of English proficiency. In the interview, they said, "The most important thing is English, mainly used to communicate with customers and introduce products"; "English is used more, in particular, reading and writing skills, and oral English is necessary, to some extent"; "the main requirement of international e-commerce is English proficiency, and oral English is not used as much as expected, unless it is used to communicate with customers face to face. But it is now conducted online, so oral English is not very needed at present". This shows that English proficiency was a necessary ability for international e-commerce talents. However, because international e-commerce is conducted online, the requirement of reading and writing skills was more prominent. Comparatively speaking, spoken English was not very important and was rarely used. In addition, it also needed English for specific purpose. Some participants said, "besides general English ability, they also need professional English related to products sold online". This shows that in addition to general English knowledge and skills, professional English knowledge and skills related to selling goods online were also needed.

In addition, with regard to cross-cultural communication ability, some participants said, "communicating with customers requires certain skills"; "some people don't know how to communicate with customers even though they are good at English". This indicates that finding new customers and selling goods to them required not only English skills, but also cross-cultural communication skills. 
Table 3. The requirements of English proficiency in international e-commerce.

\begin{tabular}{cc}
\hline Components of English Proficiency & Importance \\
\hline Powerful English reading & $45 \%$ \\
Powerful English writing & $51 \%$ \\
Fluent spoken English & $76 \%$ \\
Cross-cultural communication & $51 \%$ \\
\hline
\end{tabular}

\subsection{International E-Commerce Ability}

As shown in Table 4, the professional knowledge and skills related to international e-commerce included practical skills of online store management, product uploading and processing, foreign trade, marketing, dispute handling, data analysis, foreign trade knowledge, etc. Among them, the most important skills of international e-commerce were practical skills of online store management, foreign trade and dispute handling, all with the percentage of $74 \%$, and then, followed by product uploading and processing, marketing and data analysis, with the same percentage of $52 \%$. Less important one was foreign trade knowledge, with the percentage of $22 \%$. This shows that practical skills related to international e-commerce were more important than knowledge, especially the skill of managing online store and the skill of foreign trade.

The above findings were corroborated by the results of interviews. Some participants said in the interview that "foreign trade knowledge is not used too much, and just knowing a few technical terms is enough"; "the management of international e-commerce online store is relatively simple, and it can be learned in a short period of time". This reveals that international e-commerce did not have high requirements for foreign trade knowledge, and it was necessary to understand some technical terms, because customs declaration required of much professional knowledge in international trade was outsourced to the professional companies. In addition, compared with English skills, the skill of managing online store was easy to learn and did not need too much time. This indicates that, although the skills of managing online store and foreign trade were the most important, the difficulty is far less than the foreign language ability which required a long time to learn; although foreign trade knowledge was needed, it was used less.

\subsection{The Quality Related to International E-Commerce}

The qualities that international e-commerce talents should possess included sense of responsibility, hardworking, teamwork, independent discovering and solving problems, creativity, communication, resilience, adaptability and coordination (as shown in Table 5). The surveyed enterprises all agreed that responsibility, hardworking, and independent discovering and solving problems were the most important, all with the percentage of $100 \%$. The second most important qualities were teamwork, communication, resilience, adaptability and coordination, 
Table 4. Professional skills and knowledge of international e-commerce.

\begin{tabular}{cc}
\hline Skills and Knowledge & Importance \\
\hline Skill of managing online store & $74 \%$ \\
Product uploading and processing skill & $52 \%$ \\
Skill of foreign trade & $74 \%$ \\
Skill of marketing & $52 \%$ \\
Skill of dealing with conflicts in business & $74 \%$ \\
Skill of business data analysis & $52 \%$ \\
Knowledge of foreign trade & $22 \%$ \\
\hline
\end{tabular}

Table 5. The qualities of international e-commerce talents.

\begin{tabular}{cc}
\hline Quality & Importance \\
\hline Responsibility & $100 \%$ \\
Hardworking & $100 \%$ \\
Teamwork & $79 \%$ \\
Discovering and solving problems independently & $100 \%$ \\
Creativity & $20 \%$ \\
Communication & $78 \%$ \\
Resilience & $76 \%$ \\
Adaptability & $75 \%$ \\
Coordination & $73 \%$ \\
\hline
\end{tabular}

with the respective percentage of $79 \%, 78 \%, 76 \%, 75 \%$ and $73 \%$. This points out that, due to the characteristics of international e-commerce industry facing foreign customers, the primary quality was to find and solve problems independently, be responsible and hard-work, and the importance of creativity was not prominent, with the percentage of $20 \%$.

In the interview, the participants all mentioned the importance of qualities of international e-commerce talents. Some said, "hard-working and teamwork are very important, but it takes time to develop slowly"; "international e-commerce should take the initiative to learn and do, and to find and solve problems". This proves that, among the qualities of international e-commerce talents, it is very important to bear hardships, hard work, work as a team, and actively discover and solve problems. Some also mentioned the importance of being diligent and eager to learn, because the international e-commerce industry is developing and changing rapidly, and requires to constantly learn and update knowledge and skills.

\section{Discussion}

The results show that the ability of cross-border e-commerce talents included 
three modules. One was English ability, which was the core of international e-commerce; second module is knowledge and skills related to international e-commerce; the third was qualities of international e-commerce talents. The international e-commerce industry needs inter-disciplinary talents with practical skills, who possess the ability of foreign language and international e-commerce, and qualities required in international e-commerce industry. These three modules constitute the competency model of international e-commerce, which has similarities and differences with the competency model proposed by Marrelli (2010). Marrel's competency model includes the foreign language ability required by international e-commerce, and knowledge and skills related to international e-commerce, but it lacks the quality module suitable for the specific industry.

It was found that in the foreign language proficiency module, among Chinese international e-commerce enterprises, English was mainly used, and that the most important skills included reading and writing skills and cross-cultural communication skills. Reading and writing skills are applied to the whole process of international e-commerce, including the discovery of new customer, inquiry, offer, online store management and maintenance, order processing, etc. Cross-cultural communication skills are mainly used in finding new customers and product promotion. This finding further confirms the previous studies that foreign language ability is an indispensable component of competency model of international e-commerce (Su, 2016).

In the module of international e-commerce related knowledge and ability, it was found that online store managing skills and foreign trade skills were very important, followed by commodity uploading and processing skills, and marketing skills, but foreign trade knowledge was not so important as expected. This finding partly confirms the previous studies. Peng (2015) found that the most important thing in e-commerce is practical skills, followed by online marketing, and then online store management and maintenance. Finally, it is skills of logistics. Commodity uploading and processing skills are the important content of online store management and maintenance.

It was found that the most important thing for the qualities required of international e-commerce industry was to bear hardships and hard work, and to find and solve problems independently. Because the main customers of international e-commerce in China are foreign customers, their time is different from that of China; orders need to be processed and delivered in time, and customers' inquiries should be answered in time. All these require work overtime, and hard work is one of the necessary qualities. In addition, international e-commerce often has unexpected problems, which need to be dealt with in time. At the same time, it is necessary to actively find problems and prevent them from happening. These require the ability to actively find problems and solve them independently.

\section{Conclusion}

This study explores the competencies of international e-commerce talents by 
investigating small and medium-sized international e-commerce enterprises in China, based on which the competency model of international e-commerce was developed. The competency model consisted of three modules: foreign language competency (mainly English in China), competency of international e-commerce and quality required of international e-commerce industry. Foreign language competency included reading and writing skills, oral skills and cross-cultural communication; competency of international e-commerce included international e-commerce online store managing skills, foreign trade skills, commodity uploading and processing skills, the skill of finding new customers and marketing; qualities of international e-commerce industry include handwork, independent problem finding and solving, teamwork, diligence, resilience and adaptability. The competency model of international e-commerce developed in the study has practical guiding significance for international e-commerce talents training. Based on the competency model, specific skills and qualities are designated and cultivated for international e-commerce talents.

However, the participants of the study were mainly selected from small and medium-sized international e-commerce enterprises in Zhejiang Province of China, and thus the competency model developed has certain limitations and can be only applied to small and medium-sized international e-commerce enterprises in Zhejiang province. Future research should be extended to international e-commerce enterprises with different sizes in different regions across China, in order to build a competency model of international e-commerce generally applicable to the whole international e-commerce industry.

\section{Funding}

The study is the part of the research project of teaching reform of higher education in Zhejiang Province during the 13th Five-Year Plan (No. jg20180351), supported by Department of Education of Zhejiang Province of China.

\section{Conflicts of Interest}

The author declares no conflicts of interest regarding the publication of this paper.

\section{References}

Lucia, A. D., \& Lepsinger, R. (1999). The Art and Science of Competency Models: Pinpointing Critical Success Factors in Organizations. Jossey-Bass/Pfeiffer.

Marrelli, A. F. (2010). An Introduction to Competency Analysis and Modeling. Performance Improvement, 37, 8-17. https://doi.org/10.1002/pfi.4140370505

McClelland, D. C. (1973). Testing for Competence Rather Than for Intelligence. American Psychologist, 28, 1-14. https://doi.org/10.1037/h0034092

Peng, L. (2015). Research on the System of E-Commerce Talent Ability Based on the Enterprise's Demand. Logistics Engineering and Management, 37, 250-252.

$\mathrm{Su}$, M. (2016). On Competency Models of Cross-Border E-Commerce Talents. Research 
in Higher Education of Engineering, 3, 170-174.

Wang, J. (2015). Research Report on Cross-Border E-Commerce Talents in China. China E-Business Research Center. 